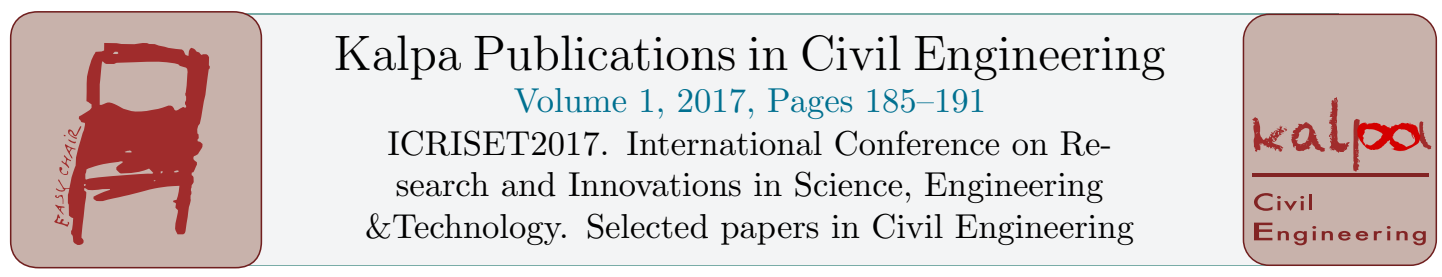

\title{
Effect of Gradation and Particle Size on Correlations between DCP Index (ASTM D6951 - 03) and Relative Density for Sand
}

\author{
M.P. Katakiya ${ }^{1}$ and A.D. Parekh ${ }^{2}$ \\ ${ }^{1}$ Charotar University of Science and Technology, Anand, India. \\ ${ }^{2}$ Dharmsinh Desai University, Nadiad, India. \\ katakiyamehul@gmail.com adp.cl@ddu.ac.in
}

\begin{abstract}
This research study was mainly focus on performing dynamic cone penetration tests according to ASTM D691 - 03 with various relative density on different gradation (poorly graded and well graded) of sand. Sand samples were collected from different region of Gujarat viz. Khanpur, Sevaliya, Ahmedabad. Well graded sand samples were prepared by mixing in different proportions of sand samples collected from above locations. Dynamic cone penetration tests were carried out in Plexiglas tank $(60 \mathrm{~cm} \times 60 \mathrm{~cm} \times 75 \mathrm{~cm})$ on three different poorly graded and three different well graded sand at different relative density of 30,50,65,75\%. Relative density of sand samples were determined according to IS : 2720 (Part 14) - 1983. Dry sand has been filled in tank up to $70 \mathrm{~cm}$ height of tank. Tamping was done with rammer $(30 \mathrm{~cm} \times 30 \mathrm{~cm} \times 1 \mathrm{~cm})$ of $9.5 \mathrm{~kg}$ weight to achieve desired density. Desired depth of penetration is $60 \mathrm{~cm}$. Dynamic cone penetration tests were performed according to ASTM D6951-03.
\end{abstract}

\section{Introduction}

Sand is required for many purposes, for example, backfill of earth retaining structures, backfill in foundation trenches, reclamation of low lands and construction of road embankments etc. In all these situations good compaction of fill should be ensured to avoid future subsidence, failure of foundation and moreover liquefaction. Relative density is the most appropriate index to control the compaction of Sand. The term used to indicate the strength characteristics in a qualitative manner is relative density (Dr) which describes the state condition of cohesion-less soils. So, relative density is a very important index for a sandy soil. The density of granular soil varies with the shape and size of grains, the gradation and the manner in which the mass is compacted. Relative density is $0 \%$ for loosest condition of sand and 100\% for densest condition of sand. Relative density of cohesion-less soil can be determined from IS: 2720 (Part - 14) - 1983.On the other hand, extensive information on the behavior of sandy soils has been obtained from laboratory tests on reconstituted and undisturbed samples. In these laboratory studies, the relative density (Dr) is commonly identified as a principal

C.D. Modhera, G.J. Joshi, D. Soni, I.N. Patel, A.K. Verma, L.B. Zala, S.D. Dhiman, D.R. Bhatt, J.M. Rathod, B.C. Goradiya, M.S. Holia and D.K. Patel (eds.), ICRISET2017 (Kalpa Publications in Civil Engineering, vol. 1), pp. 185-191 
factor influencing the deformation and strength characteristics of sands. No any available soil compaction measuring devices provide direct readout of soil density values which is main parameter to control soil compaction performance. Most of these devices are strength or stiffness measuring devices which monitor the change of in-place engineering properties due to the application of impact or vibrating force on the soil. Their output, however, provide a measure of soil densification and they can be used satisfactorily in compaction control when they are calibrated to soil relative compaction and moisture content. In order to establish the relationship between the readings of these devices and soil relative compaction, there is a need to evaluate the sensitivity of the measured strength or stiffness parameters to the changes of soil types, and compaction efforts. Dynamic Cone Penetrometer (DCP) is one of those devices and is performed on sand of known relative densities in calibration chamber.

The Dynamic Cone Penetration Test (DCPT) is a simple ground investigation technique in which a solid penetrometer is driven into the ground and the number of blows required to drive it to a given depth is recorded.

During the past decade, the DCP test has been correlated to many engineering properties such as the CBR, shear strength of granular materials, and most recently, the subgrade Resilient modulus (MR) Elastic Modulus (Es) and soil classification.

\section{Experimental Investigation}

It includes laboratory investigations for dynamic cone penetration resistance as well as relative density.

Dynamic cone penetration tests were carried out in Plexiglas tank $(60 \mathrm{~cm} \times 60 \mathrm{~cm} \times 75 \mathrm{~cm})$ on three different poorly graded and three different well graded sand at different relative density of 30 , $50,65,75 \%$. Dry sand has been filled in tank up to $70 \mathrm{~cm}$ height of tank. Whole $70 \mathrm{~cm}$ of height is divided into 14 different layers of $5 \mathrm{~cm}$ height. Uniformly distributed compactive efforts are applied at each layer of sand with tamping rammer $(30 \mathrm{~cm} \times 30 \mathrm{~cm} \times 1 \mathrm{~cm})$ of $9.5 \mathrm{~kg}$ weight to achieve required density. Desired depth of penetration is $60 \mathrm{~cm}$. Dynamic cone penetration tests were performed according to ASTM D6951-03.

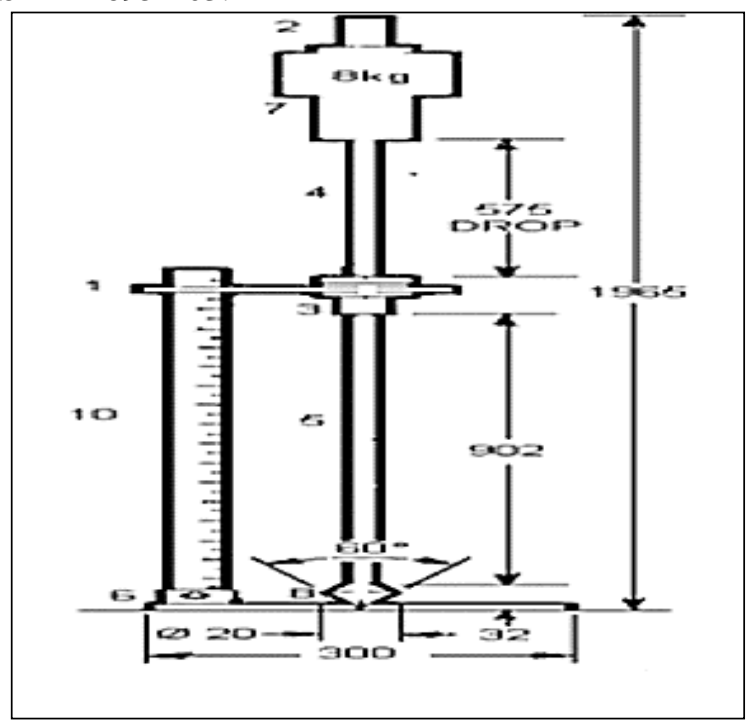

Figure 1: Dynamic Cone Penetrometer 
Where,

1 : Reading Edge

2: Handle

3 : Top edge of lower shaft

4 : Upper shaft $(\mathrm{d}=16 \mathrm{~mm})$

5 : Lower shaft $(\mathrm{d}=16 \mathrm{~mm})$

6 : Bottom of measuring scale

7 : Hammer (8 kg. weight)

8 : Cone $(\mathrm{d}=20 \mathrm{~mm})$

10 : Measuring scale

All dimensions are in $\mathrm{mm}$.

After assembling DCP, dynamic cone penetrometer is held vertically at center of the tank with one hand placed at the top of the handle. Set the instrument is such that the wildest part of the cone is flushing with the surface of the sand. In data sheet, record the current shaft reading as the starting point for blow number zero. With one hand placed on the top handle, use other hand to seat the cone by dropping the hammer from a partial height until the widest part of the cone is below the reference surface. Do not record penetration during the seating operation. Establish a reference for reading the penetration of the shaft after each blow. The reading edge is a reference level that must remain constant for accurate depth readings. On the data sheet as shown in figure 1, record the current shaft reading as the starting point for blow number zero. Raise the hammer and let it fall freely on the anvil with height of fall $575 \mathrm{~mm}$. Note down the shaft reading after each number of blow to the nearest of millimeter. Record the reading and blow count by reading the shaft to the nearest millimeter if using a metric scale. Record this as penetration for blow number 1. Operation is continued until the total penetration is less than $3 \mathrm{~mm} / \mathrm{blow}$ for ten consecutive drops or $60 \mathrm{~cm}$ depth is reached.

Table 1: Sample sheet for DCPT

\begin{tabular}{|c|c|c|}
\hline \multicolumn{3}{|c|}{ Record Sheet } \\
\hline $\begin{array}{c}\text { Cumulative } \\
\text { No. of Blows }\end{array}$ & $\begin{array}{c}\text { Penetration } \\
\text { Depth (mm) }\end{array}$ & $\begin{array}{c}\text { DCP Index } \\
(\mathbf{m m} / \text { blow })\end{array}$ \\
\hline 0 & 110 & 0 \\
\hline 1 & 251 & 141 \\
\hline 2 & 317 & 66 \\
\hline 3 & 364 & 47 \\
\hline 4 & 407 & 43 \\
\hline 5 & 443 & 36 \\
\hline 6 & 472 & 29 \\
\hline 7 & 512 & 40 \\
\hline 8 & 543 & 31 \\
\hline 9 & 572 & 29 \\
\hline 10 & 603 & 31 \\
\hline 11 & 635 & 32 \\
\hline 12 & 666 & 31 \\
\hline
\end{tabular}

Relative density of sand samples were determined according to IS : 2720 (Part 14) - 1983. 


\section{Analysis and Results}

A graph of cumulative number of blow vs. depth is prepared. Some unreliable data up to top 30 $\mathrm{cm}$ depth is neglected due to lower confinement pressure at the top of sand deposit. Such kind of graph is shown in figure 2 below.

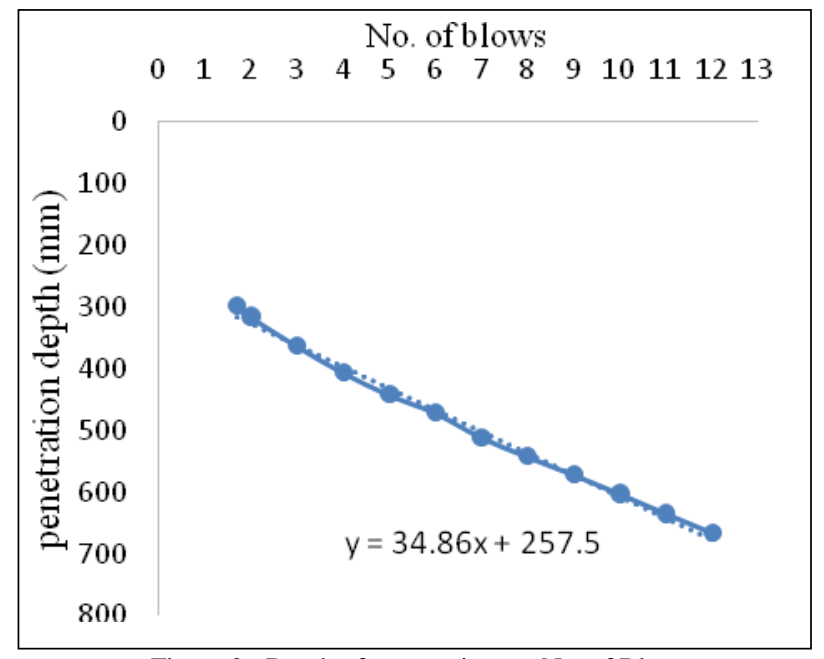

Figure 2: Depth of penetration vs. No. of Blow

It is observed that cumulative number of blows increases linearly with depth. DCPIndex was calculated from the average slope of the cumulative number of blow vs. depth plot. DCP Index for the graph shown in figure is $34.863 \mathrm{~mm} / \mathrm{blow}$.

Dynamic cone penetration test has been performed on three different sand samples collected from different region of Gujarat e.g. Khanpur, Sevaliya, Ahmedabadat different relative density of $30 \%$, $50 \%, 65 \%$ and $75 \%$. Three well graded sand samples were preparedby mixing different proportions of sand samplescollected from above locations.Properties of sand samples collected (Poorly GradedSand) and well graded sand is shown in table below.

\begin{tabular}{|l|c|c|c|}
\hline \multicolumn{1}{|c}{ Table 2: Properties of poorly graded sand } \\
\hline Sand & $\begin{array}{l}\text { Khanpur } \\
\text { Sand }\end{array}$ & $\begin{array}{l}\text { Ahmedabad } \\
\text { Sand }\end{array}$ \\
\hline$\%$ G & 6.28 & 4.2 & - \\
\hline$\%$ C S & 35.04 & 1.9 & 0.47 \\
\hline$\%$ M S & 58.0 & 75.0 & 6.5 \\
\hline$\%$ F S & 0.68 & 15.92 & 88.4 \\
\hline$\%$ S \& C & - & 2.98 & 4.63 \\
\hline$D_{60}(\mathrm{~mm})$ & 2.5 & 0.9 & 0.33 \\
\hline$D_{30}(\mathrm{~mm})$ & 1.5 & 0.5 & 0.23 \\
\hline$D_{10}(\mathrm{~mm})$ & 0.75 & 0.35 & 0.15 \\
\hline Cu & 3.3 & 2.6 & 2.2 \\
\hline Cc & 1.2 & 0.8 & 1.1 \\
\hline Sp.Gty, G & 2.7 & 2.6 & 2.59 \\
\hline
\end{tabular}




\begin{tabular}{|l|l|l|l|}
\hline$\gamma_{\max }(\mathrm{g} / \mathrm{cc})$ & 1.94 & 1.81 & 1.66 \\
\hline $\mathrm{e}_{\min }$ & 0.39 & 0.38 & 0.56 \\
\hline$\gamma_{\min }(\mathrm{g} / \mathrm{cc})$ & 1.69 & 1.53 & 1.47 \\
\hline $\mathrm{e}_{\max }$ & 0.6 & 0.63 & 0.71 \\
\hline
\end{tabular}

Table 3: Properties of well graded sand

\begin{tabular}{|l|c|c|c|}
\hline & Comb 1 & Comb 2 & Comb 3 \\
\hline$\%$ G & 1.38 & 8.93 & 10.6 \\
\hline$\%$ C S & 20.28 & 14.65 & 16.76 \\
\hline$\%$ M S & 50.2 & 51.08 & 52.53 \\
\hline$\%$ F S & 17.35 & 22.36 & 18.15 \\
\hline$\%$ S \& C & - & 2.98 & 1.96 \\
\hline $\mathrm{D}_{60}(\mathrm{~mm})$ & 1.9 & 1.6 & 1.7 \\
\hline $\mathrm{D}_{30}(\mathrm{~mm})$ & 0.75 & 0.51 & 0.65 \\
\hline $\mathrm{D}_{10}(\mathrm{~mm})$ & 0.31 & 0.17 & 0.26 \\
\hline $\mathrm{Cu}$ & 6.1 & 9.4 & 6.5 \\
\hline $\mathrm{Cc}$ & 1.0 & 1.0 & 1.0 \\
\hline $\mathrm{Sp} . \mathrm{Gty}, \mathrm{G}$ & 2.63 & 2.60 & 2.60 \\
\hline$\gamma_{\max }(\mathrm{g} / \mathrm{cc})$ & 2.16 & 2.16 & 2.23 \\
\hline $\mathrm{e}_{\min }$ & 0.22 & 0.2 & 0.17 \\
\hline$\gamma_{\min }(\mathrm{g} / \mathrm{cc})$ & 1.72 & 1.72 & 1.77 \\
\hline $\mathrm{e}_{\max }$ & 0.48 & 0.51 & 0.47 \\
\hline
\end{tabular}

Composition of three well graded sample is given below.

Combination $1(\mathbf{2 5 0}, \mathbf{1 0 0}, \mathbf{5 0})$ : This combination is having $250 \mathrm{~kg}$. ofKhanpur Sand, $100 \mathrm{~kg}$. ofSevaliya Sand and $50 \mathrm{~kg}$. of Ahmedabad sand for $400 \mathrm{~kg}$. mass of Sample.

Combination $2(\mathbf{1 3 7}, \mathbf{1 6 8}, \mathbf{9 5})$ : This combination is having $137 \mathrm{~kg}$. ofKhanpur Sand, $168 \mathrm{~kg}$. ofSevaliya Sand and $95 \mathrm{~kg}$. of Ahmedabad sand for $400 \mathrm{~kg}$. mass of Sample.

Combination $3(\mathbf{1 8 0}, \mathbf{1 4 3}, \mathbf{7 7})$ : This combination is having $180 \mathrm{~kg}$. ofKhanpur Sand, $143 \mathrm{~kg}$. ofSevaliya Sand and $77 \mathrm{~kg}$. of Ahmedabad sand for $400 \mathrm{~kg}$. mass of Sample.

Results of DCP Index for each poorly graded sample are given in table 4 and figure 3 below.

Table 4: Values of DCP Index at Different Relative density for poorly graded sand

\begin{tabular}{|c|c|c|c|}
\hline \multirow{2}{*}{$D_{R}(\%)$} & \multicolumn{3}{|c|}{ DCP Index (mm/blow) } \\
\cline { 2 - 4 } & $\begin{array}{r}\text { Khanpur } \\
\text { Sand }\end{array}$ & $\begin{array}{r}\text { Sevaliya } \\
\text { Sand }\end{array}$ & $\begin{array}{c}\text { Ahmedabad } \\
\text { Sand }\end{array}$ \\
\hline 30 & 107.02 & 118.85 & 144.41 \\
\hline 50 & 51.306 & 85.543 & 105.82 \\
\hline
\end{tabular}




\begin{tabular}{|l|l|l|l|}
\hline 65 & 34.863 & 68.368 & 100.7 \\
\hline 75 & 27.023 & 48.648 & 76.077 \\
\hline
\end{tabular}

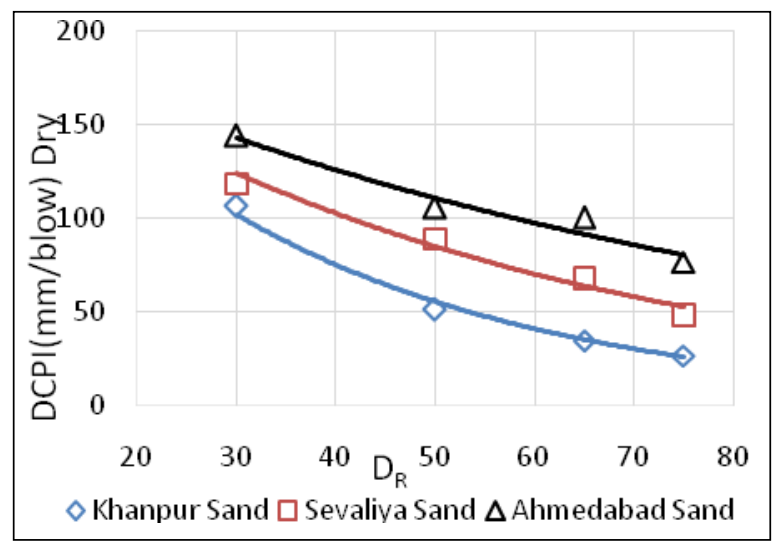

Figure 3: DCP Index vs. $D_{R}$ for poorly graded sand

DCP Index decreases exponentially with increase in value of $D_{R}$. Correlation follows the equations.

ForKhanpur sand

$\mathrm{DCPI}=255.14 \mathrm{e}_{-}{ }^{0.03 \mathrm{DR}}\left(\mathrm{R}^{2}=0.9905\right)$,

ForSevaliya sand

$\mathrm{DCPI}=215.8 \mathrm{e}^{-0.019 \mathrm{DR}}\left(\mathrm{R}^{2}=0.97\right)$,

For Ahmedabad sand.

$\mathrm{DCPI}=211.81 \mathrm{e}^{-0.013 \mathrm{DR}}\left(\mathrm{R}^{2}=0.9294\right)$.

Results of DCP Index for each well graded sand are given in table 5 and figure 4 below.

Table 5: Values of DCP Index at Different Relative Density for well graded sand

\begin{tabular}{|c|c|c|c|}
\hline \multirow{2}{*}{$\mathrm{D}_{\mathrm{R}}(\%)$} & \multicolumn{3}{|c|}{ DCP Index (mm/blow) } \\
\cline { 2 - 4 } & Comb 1 & Comb 2 & Comb 3 \\
\hline 30 & 109.32 & 171.77 & 111.3 \\
\hline 50 & 73.136 & 98.128 & 72.365 \\
\hline 65 & 38.229 & 62.36 & 44.45 \\
\hline 75 & 35.1 & 37.9 & 34.258 \\
\hline
\end{tabular}

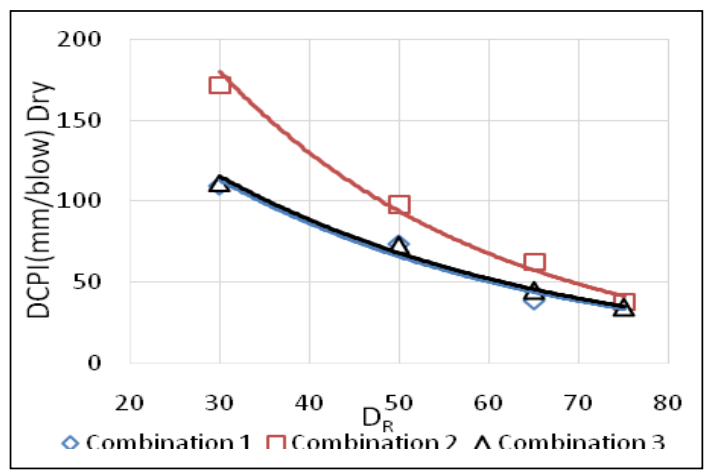

Figure 4: DCP Index vs $D_{R}$ for well graded sand 
DCP Index decreases exponentially with increase in value of $D_{R}$. Correlation follows the equations.

For Combination 1

DCPI $=254.72 \mathrm{e}^{-0.027 D R}\left(R^{2}=0.9622\right)$,

For Combination 2

$\mathrm{DCPI}=478.8 \mathrm{e}^{-0.033 \mathrm{DR}}\left(\mathrm{R}^{2}=0.9847\right)$,

For Combination 3

DCPI $=255.61 \mathrm{e}^{-0.027 \mathrm{DR}}\left(\mathrm{R}^{2}=0.9922\right)$.

\section{Conclusions}

DCP Index decrease exponentially with increase in value of relative density for each poorly graded sand as well as well graded sand.

Decrement in values of DCP Index with respect to increase in values of relative density is almost similar regardless to particle size for poorly graded sand. Whereas, decrement in values of DCP Index with respect to relative density is depend upon particle size for well graded sand.

Increase in values of DCP Index with decrease in particle size is uniform at any relative density for poorly graded sand, whereas increase in values of DCP Index with decrease in particle size, decrease with increase in relative density for well graded sand.

\section{References}

ASTM D6951 - 03, "Standard Test Method For Use Of Dynamic Cone Penetrometer InShallow Pavement Applications" ApurvkumarSiya, "Analysis of Sand Gradation Effects on Relative Density" (2014), Department of Civil Engineering, National Institute of Technology, Roukela.

G. Agrawal, "Evaluating relative compaction of fills using CPT", Willdan Geotechnical, Anaheim, California, USA.

FarshadAmini, "Potential Applications of Dynamic And Static Cone Penetrometers InMn.DOT Pavement Design And Construction" (2003), Jackson State University, Mississippi.

Md. Jahangir Alam, Mohammad ShahadatHossain and AbulKalam Azad, "Development of correlation between dynamic cone resistance and relative density of sand" (2012), Journal of Civil Engineering (IEB), Bangladesh.

Zaki A. Baghdadi, Fouad M. Ghazali and Ahmed M. Khan, "Density Prediction Using a Static Cone Penetrometer" (1990), Jeddah King Abdulaziz University, Jeddah. 